\title{
O MARKETING PESSOAL DOS INFLUENCIADORES DIGITAIS
}

\author{
Flavia Rafaela Davies ${ }^{1}$ \\ Rodrigo Oliva ${ }^{2}$
}

DAVIES, F. R.; OLIVA, R. O Marketing pessoal dos influenciadores digitais. Rev. Ciênc. Empres. UNIPAR, Umuarama, v. 20, n. 1, p. 27-41, jan./jun. 2019.

RESUMO: O mercado digital está cada vez mais presente como opção de meio para adquirir produtos, bens ou serviços devido à facilidade de acesso. A internet se tornou o principal canal pelo qual as pessoas consomem informação diariamente. Em função disso, percebe-se sucesso dos influenciadores digitais, que produzem conteúdos diferentes de acordo com seus gostos e públicos e conseguem rendimento financeiro por meio das visualizações em seus vídeos. É o caso dos youtubers, que trabalham com parcerias de marcas e empresas quando seus vídeos rendem sucessos de visualizações. Mas, para esses influenciadores destacarem-se é necessário que invistam em sua imagem e em sua forma de interação com o público, pois são seus seguidores nas redes sociais e seus inscritos na plataforma digital de vídeos que acompanham e avaliam seu trabalho. Para este estudo foi realizada uma pesquisa online, cujos dados foram analisados quantitativamente, e a partir deles foi possível realizar uma pesquisa netnográfica, analisando as estratégias utilizadas pelos influenciadores digitais para conquistar e manter seu público.

PALAVRAS-CHAVE: Marketing pessoal; Influenciadores digitais; Redes sociais.

\section{THE PERSONAL MARKETING OF DIGITAL INFLUENCES}

ABSTRACT: The digital market is increasingly present as an optional media to purchase products, goods or services due to its ease of access. The internet has become the main channel through which people consume information on a daily basis. This has also given a boom to digital influencers, who produce different content according to their tastes and audiences and achieve financial income through the viewing of their videos. This is the case of "youtubers", who work with brand and business partnerships when their video viewing skyrocket. But for these influencers to stand out, they must invest in their image and their

DOI: $10.25110 /$ receu.v20i1.6942

${ }^{1}$ Administradora e Pós-Graduanda em Consultoria Empresarial pela UNIPAR EAD. flardavies@hotmail.com.

2Professor doutor titular da UNIPAR. rodrigooliva@prof.unipar.br 
interaction with their audience, their followers in social networks and their subscribers in the digital video platform that follow and rate their work. For this article, an online survey was held, and the data were analyzed quantitatively. From the data collected, a netnographic research was developed, analyzing the strategies used by the digital influencers to conquer and maintain their audience. KEY WORDS: Personal marketing; Digital influencers; Social networks.

\section{EL MARKETING PERSONAL DE LOS INFLUENCIADORES DIGITALES}

RESUMEN: El mercado digital está cada vez más presente como opción de medio para adquirir productos, bienes o servicios, debido a la facilidad de acceso. La Internet se ha convertido en el principal canal por el cual las personas consumen información diaria. Dado a eso, se percibe el éxito de los influenciadores digitales, que producen contenidos diferentes de acuerdo a sus gustos y públicos, y logran rendimiento financiero a través de las visualizaciones en sus videos. Es el caso de los youtubers, que trabajan con aparcerías de marcas y empresas cuando sus videos rinden éxitos de visualizaciones. Pero, para que esos influyentes se destaquen es necesario que inviertan en su imagen y en su forma de interacción con el público, pues son sus seguidores en las redes sociales y sus inscritos en la plataforma digital de videos que acompañan y evalúan su trabajo. Para este artículo se realizó una encuesta en línea, cuyos datos fueron analizados cuantitativamente, y a partir de ellos fue posible realizar una investigación netnográfica, analizando las estrategias utilizadas por los influenciadores digitales para conquistar y mantener su público.

PALABRAS CLAVE: Marketing personal; Influenciadores digitales; Redes sociales.

\section{INTRODUÇÃO}

As campanhas de marketing não são mais as principais influenciadoras na hora de adquirir um produto ou serviço. Atualmente, a maioria dos consumidores buscam informações com pessoas próximas e nas comunidades on-line, pedindo conselhos, resenhas e demais dúvidas com membros de redes sociais, sites e plataformas de vídeo (KOTLER; KARTAJAYA; SETIAWAN, 2017).

Segundo Silva e Azevedo (2015) os profissionais de marketing devem formular suas estratégias de acordo com o comportamento e as necessidades de seus consumidores. Uma boa forma de identificar estes fatores é observar suas interações nas redes sociais, como se portam diante de uma propaganda de certo produto feita por influenciador digital. Os comentários feitos são uma grande 
fonte de informação para que os esforços corretos sejam aplicados na busca de satisfazer o consumidor plenamente.

É possível encontrar diversos comentários de produtos em blogs, onde os blogueiros utilizam o produto em questão por um certo tempo, e então fazem uma resenha completa sobre o produto, detalhando suas características e sua opinião acerca dele. Também há vídeos explicativos sobre como utilizar tal produto, como montá-lo, caso trate-se de equipamentos e afins. E a partir destes vídeos e comentários de usuários da plataforma de vídeo, os consumidores vão adquirindo ou mudando de opinião acerca do produto que estão buscando.

Blogueiros, youtubers ${ }^{3}$, vlogueiros são algumas das classificações dos influenciadores digitais que se destacam nas redes sociais com milhares e até milhões de seguidores. Estes influenciadores digitais são criadores de conteúdo, expondo seus estilos de vida, suas opiniões, experiências e gostos sobre diversos assuntos. Pela liberdade de expressão e pela naturalidade com que se apresentam, os consumidores tendem a confiar nas opiniões pautadas por estes influenciadores (SILVA; TESSAROLO, 2016).

E por esta imagem forte que possuem, muitas empresas procuram parcerias com os influenciadores digitais para anunciar sua marca e relatar suas experiências com os produtos anunciados. É comum que as marcas enviem seus produtos para os influenciadores que já citaram produtos semelhantes ao da marca, ou apenas para que ele conheça e transmita sua aprovação para seus seguidores. E tudo isto a um custo relativamente baixo e com uma cobertura de público muito grande (SILVA; TESSAROLO, 2016).

Este trabalho tem como objetivo analisar as estratégias que alguns influenciadores digitais utilizam para se manterem neste mercado relativamente novo e já bastante competitivo.

\section{REVISÃO BIBLIOGRÁFICA}

\subsection{Marketing}

É comum associar o marketing apenas com vendas e propagandas. No entanto, o marketing possui diversas definições que vão além do simples ato de vender algo. Kotler e Armstrong (2007, p. 4) definem o marketing como "o processo pelo qual as empresas criam valor para os clientes e constroem fortes relacionamentos com eles para capturar seu valor em troca".

Diante disto, Reichelt (2013) coloca que o objetivo marketing é atender e satisfazer as necessidades e desejos dos consumidores de forma lucrativa para a empresa, e para que isso se torne possível, é preciso assumir o desafio de co-

${ }^{3}$ Youtuber é o nome dado às pessoas que produzem conteúdo em forma de vídeos na plataforma online Youtube. 
nhecer seus consumidores e as suas necessidades.

Para obter conhecimento sobre as necessidades e desejos dos consumidores é necessário realizar a pesquisa de marketing, que consiste em identificar, coletar, analisar e disseminar as informações. Este conjunto de ações é realizado com o objetivo de auxiliar a tomada de decisões relacionadas à identificação e solução de problemas em marketing (MALHOTRA et al., 2005).

A pesquisa auxilia também avaliar a participação de mercado e a eficácia da utilização do mix de marketing, composto de marketing ou 4 P's, que consiste na combinação de produto, preço, praça e promoção (KOTLER; ARMSTRONG, 2007).

O produto pode ser tangível, no caso de um bem, ou intangível como um serviço. Existem cinco níveis de produtos: produto núcleo, que é o que o cliente realmente procura ao comprar este produto, visando sua funcionalidade; o produto básico possui o mínimo de atributos de um produto, mas já constitui uma oferta ao mercado; a expectativa das pessoas sobre um produto constitui o produto esperado, e o produto ampliado, quando as empresas aumentam o nível de seus produtos para se destacar de seus concorrentes (REICHELT, 2013).

Magalhães e Sampaio (2007) estabelecem preço como o esforço exigido do consumidor final, o que o consumidor terá que despender em troca do produto ou serviço. Quanto mais a colocação ‘valor oferecido/custo exigido' for favorável para o consumidor, mais ele terá a sensação de que o produto ou serviço é barato, e quanto mais desfavorável, mais ele terá a sensação de que o produto ou serviço é caro. O mais adequado seria estabelecer o ponto ótimo, que é a melhor margem para a empresa dentro dos limites da disponibilidade do consumidor para pagar.

Praça, ou distribuição é o composto responsável por fazer com que o produto ou serviço chegue ao seu consumidor final. Para que o produto esteja disponível aos consumidores no lugar certo e na hora certa, os chamados intermediários de marketing participam desse processo logístico de entrega. São esses intermediários as equipes interna e externa de vendas, distribuidores, agentes, varejistas, atacadistas, representantes, concessionários, franqueados e outros (REICHELT, 2013).

A promoção, como o próprio nome traduz, é o "P” responsável por tornar o produto ou serviço conhecido, engloba todas as formas de comunicação utilizadas pela empresa. Quais veículos, quais mídias e quais formas de abordagem sobre a imagem, função e benefício do produto serão utilizados para expô-lo. Algumas ferramentas de promoção são a propaganda, promoção de vendas, marketing pessoal, marketing direto (REICHELT, 2013).

A partir do conhecimento de uma necessidade, e tendo sua solução, é necessário comunicá-la aos interessados. A comunicação é fundamental no pro- 
cesso de marketing, devendo ser planejada e adaptada aos variados públicos ou mercados, pois cada vez mais a comunicação de marketing está buscando estreitar relações com mercados mais definidos. Através da comunicação integrada de marketing, as organizações integram e coordenam seus diversos canais de comunicação a fim de transmitir uma mensagem direta, limpa e atrativa para a organização e/ou sua marca (KOTLER; ARMSTRONG, 2007).

A comunicação integrada de marketing envolve identificar o público-alvo e elaborar cuidadosamente a programação promocional para despertar no público a reação ou emoção desejada pela empresa. E para que essa comunicação seja eficaz, é necessário compreender as etapas da comunicação e seus atores envolvidos (KOTLER; ARMSTRONG, 2007).

Segundo Chiavenato (2003), são seis os elementos necessários à comunicação: 1) Fonte: pessoa ou coisa que emite as mensagens; 2) Transmissor: processo ou equipamento que processa a mensagem, transmitindo-a da fonte para o canal; 3) Canal: equipamento que intermedia entre o transmissor e o emissor; 4) Receptor: processo ou equipamento que recebe a mensagem no canal; 5) Destino: pessoa ou processo a quem é destinada a mensagem no ponto final; 6) Ruído: perturbações, barulhos, sonidos que atrapalham a compreensão das mensagens transmitidas.

Figura 1: processo de comunicação

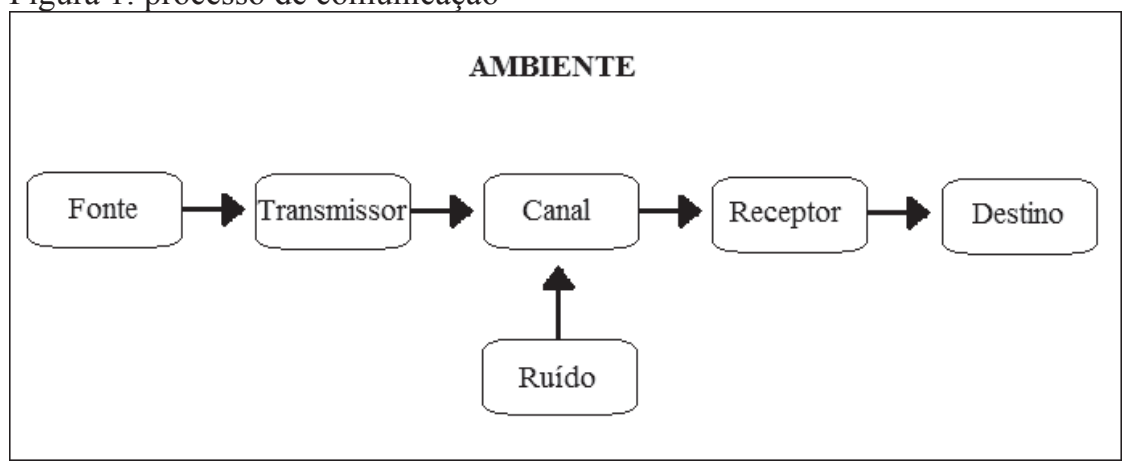

Fonte: Adaptado de KOTLER e ARMSTRONG, 2007.

Conforme a Figura 1, a comunicação ocorre em etapas, e, no elemento ruído, podem ocorrer alterações na percepção do conteúdo da mensagem. São esses ruídos que devem ser identificados para preveni-los ou repará-los, de forma que a mensagem recebida possua o mesmo conteúdo quando foi transmitida.

\subsection{Marketing pessoal e de relacionamento}


O marketing não é utilizado somente pelas empresas, mas também por pessoas. O marketing pessoal é um conjunto de ações a fim de obter sucesso pessoal e/ou profissional, seja para conquistar uma nova posição frente ao mercado de trabalho ou manter a atual, e essas ações são voltadas para a promoção de uma imagem pessoal, uma personalidade (RITOSSA, 2012).

Com a crescente competitividade e desmitificação do marketing pessoal a partir do conhecimento real de seu significado, ele passou a ser aceito no mercado, posicionando-se como parte da gestão da carreira e desenvolvimento pessoal e profissional. Pode-se então caracterizar o marketing pessoal como um "conjunto de estratégias e ações individuais que visam a transmitir uma imagem relevante para atrair e desenvolver contatos e relacionamentos significativos" (RAHME, 2017, p. 142).

Para Rahme (2017), a construção de uma imagem positiva na perspectiva das pessoas passa pelas seguintes etapas: Autoconhecimento: capacidade do indivíduo conhecer a si próprio; Visão de futuro: saber o que o indivíduo quer; Autodesenvolvimento: definição clara do que quer e como superar os desafios e aproveitar as oportunidades; Relacionamentos: manutenção de relacionamentos saudáveis e que impulsionem seu desenvolvimento pessoal e coletivo; Comunicação: nível de efetividade com que as verdades são transmitidas aos outros e se há algum resultado positivo no impacto causado.

Dessa forma, além de trabalhar o marketing pessoal, é necessário dar atenção ao marketing de relacionamento, pois o principal objetivo deste último é aproximar as empresas de seus clientes, ou, neste caso, as personalidades, figuras públicas aos seus clientes (ALVES; BARBOZA; ROLON, 2014).

Esta proximidade entre empresa e cliente pode trazer diversos benefícios para ambas as partes como benefícios sociais, psicológicos, econômicos e de customização. Os benefícios sociais provêm de relacionamentos amistosos entre empresa e clientes, podendo o cliente ter um relacionamento personalizado, como psicológicos, segurança, confiança, conforto, proximidade com a empresa ou marca. Descontos em compras ou rapidez no atendimento são benefícios econômicos, e, de customização, benefícios e serviços adicionais oferecidos ao cliente pelas constantes compras (ALVES; BARBOZA; ROLON, 2014).

Freire, Lima e Leite (2009) colocam que manter e fidelizar um cliente exige que o relacionamento ultrapasse o tradicional e passe a ser uma experiência, um encantamento com a atenção e preocupação da empresa com a satisfação do cliente não só pelo produto ou serviço adquirido, mas também no pós-compra, sanando suas dúvidas ou queixas. Exige-se tempo e dedicação com o marketing de relacionamento, pois este é um esforço contínuo que requer conhecimento do valor dos seus clientes e a construção de uma cadeia de relacionamentos para criar valor ao cliente (FREIRE; LIMA; LEITE, 2009). 
Existem vários meios de manter contato com os clientes, e uma forma atual é por meio da internet, com websites, blogs e outras redes sociais online. Observa-se que o crescente uso das tecnologias como celulares com acesso à internet criou um novo tipo de mercado, o mercado digital (JUNIOR; BATISTA; AZEVEDO, 2015).

Uma das vantagens do marketing digital é uma maior proximidade de contato com seus clientes e rápida avaliação do feedback dos resultados das ações e estratégias da empresa devido à rapidez com que as informações surgem e se propagam no meio digital (JUNIOR; BATISTA; AZEVEDO, 2015).

Desta forma, o cliente não é visto mais somente como público-alvo, mas também como ator, como participante, uma vez que suas ideias e comentários podem interferir, decidir, promover mudanças neste ambiente de múltiplas interações. E para que esta constante interação, que é tão pública não gere efeitos negativos para a empresa, é necessário um constante e cuidadoso planejamento sobre como interagir com os clientes nas redes sociais e demais plataformas digitais (RAHME, 2017).

\section{MÉTODO}

Para esta pesquisa foi utilizada a metodologia mista, que é a combinação dos métodos qualitativo e quantitativo. A abordagem qualitativa é utilizada na análise e interpretação de fenômenos humanos com o objetivo de obter uma visão detalhada, complexa e abrangente destes. E a abordagem quantitativa também é utilizada na pesquisa sobre problemas humanos e sociais, composta por variáveis medidas por valores numéricos e analisadas estatisticamente afim de quantificar e informar dados (FAZENDA; TAVARES; GODOY, 2017).

A pesquisa qualitativa foi feita por meio da netnografia, um método adaptado da etnografia para estudar o comportamento humano em comunidades on-line. A netnografia é uma forma de conexão com as pessoas, pois o netnógrafo envolve-se nas conversas e desenvolve certa empatia pelos participantes das comunidades online em que ele está inserido analisando as interações. (KOTLER; KARTAJAYA; SETIAWAN, 2017). Dessa forma, serão analisados os perfis nas redes sociais e canais nas plataformas de vídeo on-line dos influenciadores digitais mais citados no questionário aplicado para esta pesquisa, bem como os comentários e notáveis percepções sobre estas personalidades.

Para realizar a pesquisa quantitativa foi utilizado o questionário. $\mathrm{O}$ questionário é a forma mais utilizada para coletar dados, possibilitando medir as informações obtidas com exatidão. Ele é composto por um conjunto de questões logicamente relacionadas com um problema central (CERVO; BERVIAN; SILVA, 2007). As questões foram fechadas, com limitação de respostas, devendo o 
questionando escolher dentre as opções disponíveis, e, algumas abertas, permitindo respostas livres, embora mais difíceis de serem codificadas, são necessárias para esta pesquisa.

O questionário foi elaborado online com a Ferramenta Formulários Google 4 , um aplicativo do Google Drive. Ele começou a ser respondido no dia 11 de setembro de 2017, sendo divulgado por meio de redes sociais online e enviado via e-mail para diversas pessoas. O questionário é composto por 12 questões, sendo 10 fechadas de múltipla escolha e 2 abertas para respostas livres. $\mathrm{O}$ questionário ficou aberto até o dia 11 de outubro de 2017, após este período os resultados foram analisados e apresentados no tópico a seguir.

\section{RESULTADOS E DISCUSSÃO}

O questionário feito para esta pesquisa ficou disponível entre os dias 11 de setembro e 11 de outubro de 2017 pela ferramenta Formulários Google e foi respondido por pessoas nas seguintes faixas etárias, $32,7 \%$ entre 22 e 29 anos, $28,8 \%$ entre 16 e 21 anos, $22,1 \%$ entre 30 e 39 anos e $8,7 \%$ entre 15 anos ou menos. Desse total, $84,6 \%$ possui mais de um aparelho com acesso à internet $\mathrm{e}$ $13,5 \%$ possui apenas um aparelho com acesso à internet.

Na seguinte questão "Qual destes aparelhos você utiliza para ter acesso à internet?", os smartphones são os mais utilizados, com 94\%, seguido do notebook com 66\%, Smart TV 38,5\%, PC (personal computer) 35,6\%, tablet 15,4\% e, outros $9,6 \%$.

Os smartphones são capazes de conectar um indivíduo a uma rede de outros, as chamadas redes sociais. Devido aos mais diversos aplicativos de relacionamento, os smartphones se tornaram o principal canal de conexão e comunicação entre as pessoas (COUTINHO, 2014).

Na questão "Você possui alguma rede social?", os indivíduos que possuem totalizaram 97\%. Deste percentual, as redes sociais que os questionados possuem encontram-se representadas na figura 2.

${ }^{4}$ https://www.google.com/intl/pt-BR/forms/about/ 
Figura 2: Redes sociais que os questionados possuem.

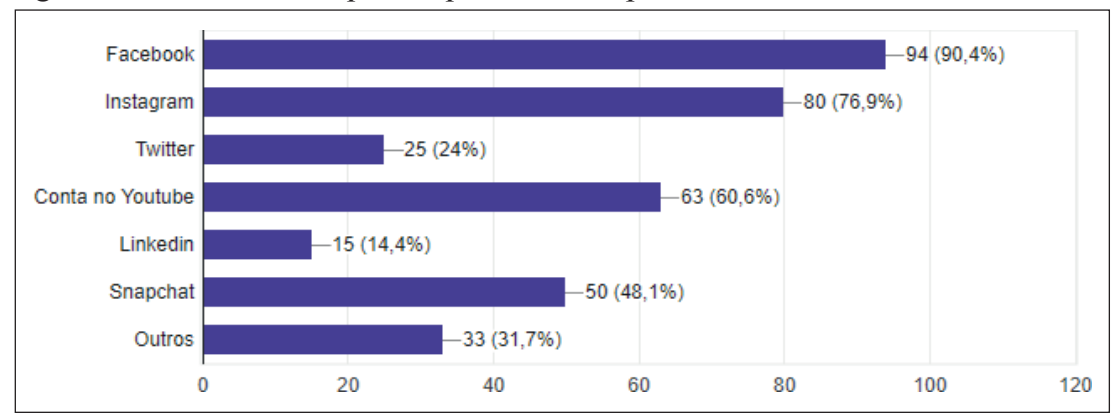

Fonte: Elaborado pelos autores, 2017.

O Facebook lidera na porcentagem das redes sociais, com $91,2 \%$, seguido do Instagram 77,5\% e conta na plataforma de vídeos Youtube 60,8\%.

Na questão seguinte, "Você costuma buscar opiniões, comentários e resenhas na internet sobre algo que deseja adquirir?", os resultados estão expostos na figura a seguir.

Figura 3: Porcentagem das pessoas que buscam opiniões na internet.

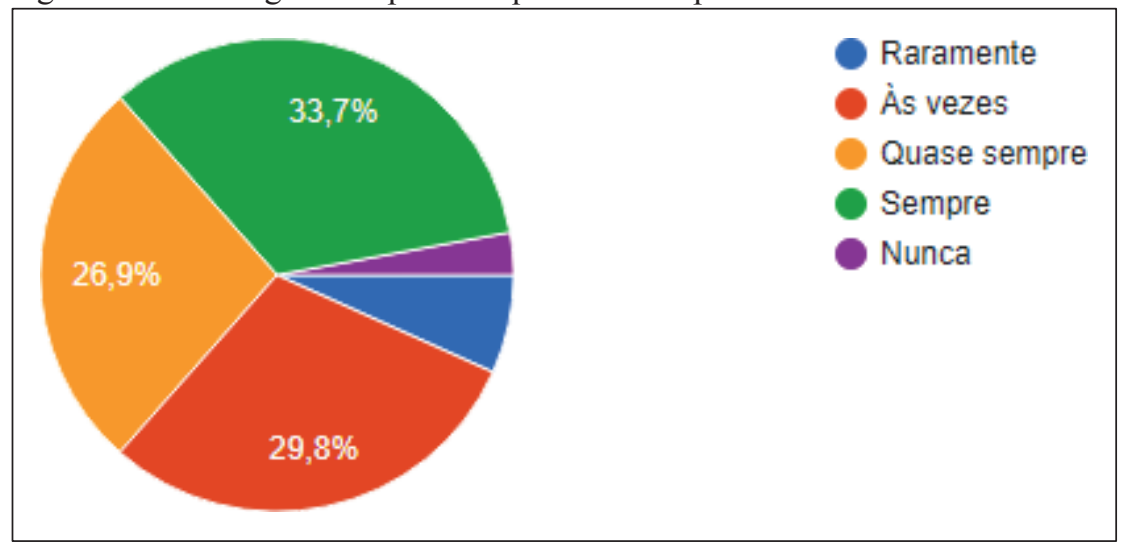

Fonte: Elaborado pelos autores, 2017.

E dentre as redes sociais escolhidas pelos questionados para buscar opiniões, comentários ou ideias, o Youtube lidera com 54,9\%, onde os youtubers postam seus vídeos sobre mais diversos assuntos, possuem milhares, até milhões de inscritos em seu canal. Em seguida estão a opção outros $(47,1 \%)$, Facebook (44,1\%), Instagram (30,4\%), Twitter (7,8\%) e Linkedin e Snapchat, ambos com 
$(3,9 \%)$.

Dos questionados, 66,7\% afirmam se sentir influenciados pelos comentários e experiências de alguns influenciadores digitais. O restante 33.3\%, não se sentem influenciados. Ainda, é possível perceber que 57,8\% acompanham algum influenciador digital nas redes sociais, dentre youtubers, blogueiros e vlogueiros.

Os assuntos mais buscados por quem acompanha os influenciadores digitais nas redes sociais podem ser observados na figura a seguir.

Figura 4: Assuntos mais buscados.

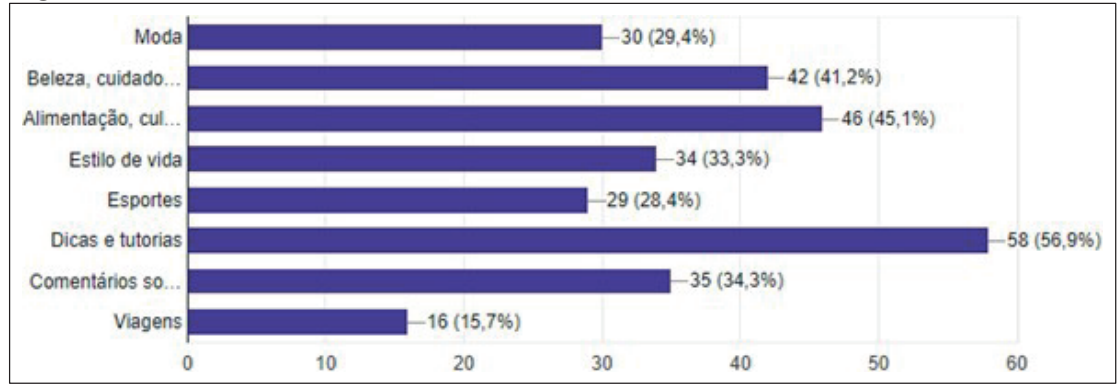

Fonte: Elaborado pelos autores, 2017.

As duas últimas questões do questionário eram abertas. Na primeira questão "Quais influenciadores digitais você mais ouve falar? (youtubers, blogueiros, vlogueiros)", houve muitas respostas como "não conheço, nenhum, não recordo", mas também houve muitos nomes conhecidos como Whindersson $\mathrm{Nu}-$ nes, Kéfera, Kim Rosacuca, Gabriela Pugliesi, Danielle Noce, Felipe Neto, Niina Secrets, Boca Rosa, Felipe Franco, Camila Coelho entre outros nomes.

Na segunda questão aberta "Quais os influenciadores digitais você costuma acompanhar pelas redes sociais? (youtubers, blogueiros, vlogueiros)", as respostas foram similares às da questão anterior, com respostas como "nenhum, não recordo, não sei responder", e nos nomes citados também similares aos citados na questão anterior com alguns a mais, como Manual do Mundo, Hugo Gloss, Padre Fábio de Melo, TPM, pra que te quero?, Flavia Calina, Julia Doorman, entre outros.

Como descrito na metodologia, três nomes citados serão analisados, segundo a pesquisa netnográfica, seus conteúdos produzidos, marcas ou produtos que anunciam, número de seguidores em suas redes sociais e comentários nas mesmas.

Conforme indicado por Kotler, Kartajaya e Setiawan (2017), é comum na pesquisa netnográfica que o pesquisador revele seus propósitos e peça permissão aos membros da comunidade que ele irá observar. Antes de realizar a 
pesquisa netnográfica, foram enviados e-mails aos influenciadores mais citados no questionário pedindo permissão para citar seus nomes e fazer as observações necessárias. Três influenciadores responderam e permitiram serem observados e citados neste trabalho.

O primeiro influenciador digital a ser analisado será a Kim Rosacuca, uma youtuber com mais de 4,5 milhões de inscritos em seu canal homônimo no Youtube $^{5}$, plataforma digital de vídeos. Em seus vídeos, ela dá dicas, ideias de beleza, ensina fazer diversas coisas, muitas delas a partir de materiais e objetos que costumam ser encontrados em casa, os chamados DIY (do it yoursel), vlogs esporádicos, web série fictícia e tutoriais de maquiagem.

Na rede social Instagram ${ }^{6}$, Kim conta com mais de 1,5 milhões de inscritos. Entre seus mais de 900 posts, há conteúdos patrocinados, em geral de cosméticos e roupas, e todos os seus posts contam com milhares de curtidas e centenas de comentários com conteúdos de expressão de carinho e admiração por parte de seus seguidores. Em sua página no Facebook $^{7}$ ela conta com mais de 400 mil seguidores, ficando claro que o Youtube e o Instagram são as plataformas digitais de maior visibilidade para a influenciadora digital. Seus vídeos de maiores visualizações são de dicas e DIY.

O vídeo mais famoso conta com aproximadamente 7,1 milhões, mais de 450 mil curtidas e mais de 5.600 mil comentários no vídeo sobre como remover cravos do nariz em 2 minutos. Apesar de a maioria dos conteúdos dos seus vídeos serem sobre reaproveitar materiais em objetos novos, em uma entrevista deste ano para o site Capricho, Kim é descrita como "a maior youtuber de beleza do Brasil"". Nestes vídeos que a youtuber ensina fazer algo, em sua maioria ela ensina a fazer kits de maquiagens com maquiagens que provavelmente as pessoas já teriam em casa.

Em seus vídeos, Kim Rosacuca chama carinhosamente seus seguidores de "cuquinhos", referência ao seu nome, e estes retribuem o mesmo sentimento em seus comentários nos vídeos e em seus posts nas redes sociais.

O segundo influenciador digital, Danielle Noce também é youtuber com seu $\mathrm{canal}^{9}$ que leva seu nome no Youtube. Os conteúdos produzidos são receitas, em sua grande maioria de bolos, tortas doces e outras sobremesas, e viagens por diversos roteiros pelo mundo. Nos vlogs de viagens, Danielle e seu esposo, Paulo, exploram lugares turísticos e outros nem tanto, experimentando a culinária local, buscando referências para suas receitas, pois é confeiteira profissional.

\footnotetext{
${ }^{5}$ https://www.youtube.com/user/TheRosaCuca/featured

${ }^{6} \mathrm{https} / / /$ www.instagram.com/kimrosacuca/

${ }^{7}$ https://www.facebook.com/therosacuca/

${ }^{8}$ Disponível em: https://capricho.abril.com.br/tv-capricho/ch-entrevista/ch-entrevista-kim-rosacucarelembra- seu-primeiro-tutorial/. Acesso em: 17 de out. 2017.

${ }^{9}$ https://www.youtube.com/user/nocedanielle/featured
} 
Entre os roteiros feitos pelo casal, Los Angeles, Istambul, Nova York, Paris, Bahia, Amazônia, Islândia, entre outros, disponíveis na playlist de viagens em seu canal. $\mathrm{O}$ vídeo mais visualizado de viagens foi do destino às ilhas Mallorca e Menorca na Espanha, com mais de 1,4 milhões de visualizações. Esta viagem foi oferecida pelo governo da Espanha para que Danielle divulgasse em seu canal suas experiências no local.

Dentre os vídeos de culinária, as receitas de bolo somam números de visualizações como 1,7 milhões, 1,5 milhões, 1,1 milhões de visualizações, além de números próximos em vídeos de outros doces. Autora de três livros, dois deles sobre receitas, Danielle Noce ainda mantêm um site $e^{10} \mathrm{com}$ as receitas que ela reproduz em seus vídeos além de outras receitas, inclusive salgadas. Mas seu foco e sua especialização são na confeitaria. O seu site, anteriormente estava sob o domínio www.ickfd.com.br e agora está integrado a outros conteúdos, ficou sob o endereço www.daninoce.com.br, é o "maior e mais completo site de confeitaria do Brasil"'l1.

Danielle e o esposo contracenam nos vídeos, onde ele filma suas receitas e faz comentários bem-humorados, o que gera comentários positivos em seus vídeos de seus espectadores elogiando a sinergia do casal ao executar as receitas. Paulo também a acompanha nas viagens. Nestes, os dois dividem a posse da câmera para que os dois possam compartilhar suas experiências pela gastronomia local e pelos destinos que eles visitam.

E por último, um canal no Youtube também sobre culinária, receitas de doces e esporadicamente salgados com o tema e pretensão de aplacar a vontade por doces característica da famosa tensão pré-menstrual. Por isso o nome sugestivo do canal, TPM, pra que te quero? ${ }^{12}$. Nele, Juliana Ferraz apresenta o conteúdo e reproduz as receitas, filmadas pelo seu esposo Victor. No entanto, o casal nada lembra Danielle e Paulo, pois, a apresentação, produção das receitas e interação do casal revelam seu jeito próprio, sem qualquer pretensão de se assemelhar a outros youtubers que trabalham em casal.

Com mais de 400 mil inscritos, o vídeo em que Ju, como ela e seus seguidores e espectadores a chamam faz um bolo de bombom de morango acumula mais de 800 mil visualizações. Suas receitas são visualmente muito atrativas, dando a sensação de que são realmente perfeitos para acalmar a necessidade de comidas doces pelas mulheres durante seus dias de dilemas particularmente femininos.

\footnotetext{
${ }^{10} \mathrm{http}: / /$ www.daninoce.com.br/

${ }^{11}$ Disponível em: https://www.opovo.com.br/jornal/buchicho/2017/02/doce-como-a-vida-deve-ser. html. Acesso em: 17 de out. 2017.

${ }^{12}$ https://www.youtube.com/channel/UCyEMfGboxLhNCtg05MfRKnA/featured
} 
Na rede social Instagram, o perfil ${ }^{13}$ do canal possui mais de 150 mil seguidores. Fotos muito bem produzidas, com imagens de suas receitas que levam seus seguidores ao delírio, resultando em comentários hiperbólicos, ou seja, com usos de palavras no sentido exagerado para expressar a vontade e desejo de experimentar o doce da imagem.

\section{CONSIDERAÇÕES FINAIS}

O mercado digital está cada vez mais em ascensão e, aqueles que trabalham nele tem que inovar constantemente para acompanhar as rápidas mudanças que este ambiente proporciona. Existem influenciadores digitais de diversos segmentos: beleza, moda, esporte, culinária, viagens, curiosidades, etc. E esses se veem obrigados a diferenciar seu conteúdo para não se tornar "menos" interessante que o outro youtuber, vlogueiro, blogueiro.

A youtuber Kim Roscacuca não é a única que produz conteúdos sobre dicas, tutoriais e DIY, pois este tipo de conteúdo é largamente encontrado nos vídeos do Youtube, e em muitos sites também. O diferencial percebido de Kim é a maneira como ela conduz seus vídeos, de uma maneira descontraída, às vezes iniciando seus vídeos com histórias temáticas representadas por ela, relatando por meio da personagem, a necessidade por aquele produto ou objeto que ela virá ensinar a fazer em seguida no vídeo.

Kim se destaca pelos seus vídeos engraçados, seu jeito descontraído, o que lhe garantiu um grande público infantil, facilmente percebido por meio dos comentários em seus vídeos. Tamanho este público, que a youtuber fez alguns vídeos em que ensina a fazer um kit de maquiagem para crianças, e, o mais visualizado dele possui 3,6 milhões de visualizações.

No Instagram, a hashtag ${ }^{14}$ \#aprendicomakim conta com mais de 3.900 publicações de coisas que seus seguidores aprenderam a fazer em seus vídeos. Devido ao seu sucesso nas redes sociais e nos vídeos do Youtube, Kim já fez algumas participações em quadros do programa É de Casa, da Rede Globo, ensinando trabalhos manuais.

Danielle Noce faz sucesso com seus bolos e doces cheios de técnicas, detalhes minimalistas nos utensílios, a produção de vídeos impecável, e a interação com o esposo que filma suas receitas e faz comentários e dá palpites nada especialistas na confeitaria diverte o público, que comenta de forma positiva e humorada em seus vídeos. Algumas receitas possuem conteúdo patrocinado, de marcas como Fleischmann, Nestlé, Nescafé Dolce Gusto e a rede de hipermercados Extra.

\footnotetext{
${ }^{13} \mathrm{https}: / /$ www.instagram.com/tpmpraquetequero/?hl=pt-br

${ }^{14}$ Expressão bastante utilizada para categorizar conteúdos publicados em redes sociais.
} 
Da mesma forma, o canal TPM, pra que te quero?, também possui vídeos de suas receitas patrocinados pela marca Fleischmann. Muito próxima do seu público no canal, Juliana Ferraz sempre faz em seus vídeos alguma pergunta e pede que seus inscritos a respondam nos comentários. Assim ela interage com quem a assiste e demonstra interesse pelas opiniões e comentários dos seus espectadores.

A internet é livre, repleta de pessoas com todos os tipos de interesses e gostos, assim como há influenciadores digitais que falam de diversos assuntos. Da mesma forma, também há vários influenciadores que falam de um mesmo assunto, por isso cabe a eles explorar seu potencial, estar atendo ao feedback que seu público lhe dá a todo momento, e, a facilidade como se tem acesso a esse feedback é um grande ponto positivo.

Portanto, sugere-se que os influenciadores digitais, e os que querem adentrar neste mercado, pensem bem no tema ou assunto que irão abordar, a forma como se apresentar ao público, e, principalmente, estejam atentos aos comentários de seus seguidores e espectadores, pois são estes que os acompanham e podem lhes oferecer dicas e sugestões válidas. E claro, que estes influenciadores tenham responsabilidade sobre seus conteúdos produzidos e suas opiniões, visto que a sua própria denominação já diz: influenciador.

\section{REFERÊNCIAS}

ALVES, E. B.; BARBOZA, M. M.; ROLON, V. E. K. Marketing de relacionamento: como construir e manter relacionamentos lucrativos? Curitiba: InterSaberes, 2014.

CERVO, A. L.; BERVIAN, P. A.; SILVA, R. da. Metodologia científica. São Paulo: Pearson Prentice Hall, 2007.

CHIAVENATO, I. Introdução à teoria geral da administração: uma visão abrangente da moderna administração das organizações. 7. ed. rev. e atual. Rio de Janeiro: Elsevier, 2003.

COUTINHO; G. L. A era dos smartphones: um estudo exploratório sobre o uso dos smartphones no Brasil. 2014. Disponível em: http://bdm.unb.br/ bitstream/10483/9405/1/2014_GustavoLeuzingerCoutinho.pdf. Acesso em: 22 set. 2017.

FAZENDA, I. C. A.; TAVARES, D. E.; GODOY, H. P. Interdisciplinaridade na pesquisa científica. Campinas, SP: Papirus Editora, 2017. 
FREIRE, C. P. S.; LIMA, M. V. S.; LEITE, B. C. Marketing de Relacionamento e sua influência na conquista e manutenção de clientes. 2009. Disponível em: http://periodicos.unifacef.com.br/index.php/rea/article/viewFile/369/355. Acesso em: 04 set. 2017.

FERREIRA JUNIOR, A. B.; AZEVEDO, N. Q. Marketing digital: uma análise de mercado 3.0. Curitiba: InterSaberes, 2015.

KOTLER, P.; ARMSTRONG, G. Princípios de marketing. 12. ed. São Paulo: Pearson Prentice Hall, 2007.

KOTLER; P.; KARTAJAYA, H.; SETIAWAN, I. Marketing 4.0. Rio de Janeiro: Sextante, 2017.

MAGAlHÃES, M. F.; SAMPAIO, R. Planejamento de marketing: conhecer, decidir, agir. São Paulo: Pearson Prentice Hall, 2007.

MALHOTRA, N. K. et al. Introdução à pesquisa de marketing. São Paulo: Prentice Hall, 2005.

RAHME, L. H. Comunicação, marketing e novas tecnologias na gestão de pessoas. Curitiba, InterSaberes, 2017.

REICHELT, V. P. Fundamentos de marketing. Curitiba: InterSaberes, 2013.

RITOSSA, C. M. Marketing pessoal: quando o produto é você. Curitiba: InterSaberes, 2012.

SILVA, B. A.; AZEVEDO, S. B. O comportamento do consumidor do e-commerce: fatores que influenciam o processo decisório de compra. 2015. Disponível em: http://www.inovarse.org/sites/default/files/T_15_205.pdf. Acesso em: 18 set. 2017.

SILVA, C. R. M.; TESSAROLO, F. M. Influenciadores digitais e as redes sociais enquanto plataformas de mídia. 2016. Disponível em: http://portalintercom. org.br/anais/nacional2016/resumos/R11-2104-1.pdf. Acesso em: 18 set. 2017. 